\section{Nuclear building-down}

SIR - In your 5 April 1984 issue (p.490), Stephen Salter presents an intriguing formula for multilateral nuclear disarmament. The Salter proposal is original and well thought out but is, unfortunately, flawed by the unrealistic assumption that either superpower would allow his strategic nuclear force to be restructured by his adversary. The scheme calls for a level of bilateral collaboration we find highly implausible.

There is another possible path to nuclear arms reduction that we think has not so far received sufficient attention. This path entails the simultaneous build-up of defensive systems and the build-down of offensive weaponry - something we have termed, in a recent issue of Foreign Policy, defence-protected build-down (DPB). In other words, were either the United States or the Soviet Union unilaterally and incrementally to reduce offensive capabilities while simultaneously deploying defensive systems, a winding down of the arms race could result without producing instability or vulnerability in the strategic balance.

Arms controllers have long considered the build-up of defensive systems to be destabilizing and prone to exacerbating the arms race. The deployment of defensive systems on a gradual or incremental basis need not be destabilizing, however, if it is accompanied by a concomitant and compensatory arms reduction. Since the initiator would gain no strategic advantage from this strategy, his adversary would have no compelling reason to escalate the arms race. We would simply be exchanging one kind of parity (based on mutually assured destruction) for another (based on mutually assured survival).

In a simplified example of how DPB might work, let us assume that the United States and the Soviet Union have achieved parity with 1,000 warheads each. A USdeployed defensive system capable of destroying 10 per cent of the Soviet warheads in an all-out Soviet attack would leave Moscow with only 900 deliverable weapons. This situation would permit Washington to dismantle 100 of its warheads and still maintain the offensive balance. We would not advocate that the United States should continue DPB indefinitely in the absence of a positive Soviet response. Although DPB can be initiated unilaterally, it must eventually evoke a willingness on the part of the other side to join in.

The difficulty in estimating the technical effectiveness of a defensive system is, of course, a serious potential shortcoming of a DPB strategy. Given uncertainties and the prevailing use of worst-case analysis, US planners in the above example will tend to provide low estimates of the defence's technical effectiveness (since it would then dismantle fewer of its warheads than if the effectiveness were high), whereas the
Soviet Union, in contemplating a response to the US action, would naturally estimate the effectiveness to be high. By initially proceeding with DPB in very small increments, however, we can avoid serious discrepancies and stay within the confines of the 1972 Anti-Ballistic Missile (ABM) Treaty, while assessing the Soviet response. The importance of DPB in the beginning resides not in the level of protection provided but in the initiation of a windingdown process and the establishment of a new international norm of behaviour based on offensive arms reduction rather than expansion.

The DPB strategy asserts that defensive systems need not be perfect, or even close to perfect, to achieve a most important goal; namely, a reduction in the level of superpower confrontation and a lessening of the catastrophe that befalls all of us in the event that deterrence fails. The DPB strategy, therefore, is not intended to be a "quick fix" to eliminating our vulnerability. Rather it is seen as a vehicle for making a long-term and evolutionary transition to a safer, defence-oriented world.

JACK N. BARKENBUS

Institute for Energy Analysis,

ALVIN M. WEINBERG

PO Box 117 ,

Oak Ridge,

Tennessee 37830, USA

\section{Nuclear proliferation}

SIR - As a result of a misunderstanding, you altered part of my letter on the NonProliferation Treaty (NPT) (Nature 26 April, p.768), and in the process altered the meaning intended.

In the penultimate paragraph as printed, the implication conveyed is my concern that both Pakistan and Argentina now have the facilities to make nuclear weapons. However, in my original letter I stated that this being the case "it is crucial that the (current) nuclear weapons states show they do not intend to take military advantage of their own civil nuclear programmes, whilst demanding through Articles I and III of the NPT that (current) non-nuclear weapon states forgo the opportunity to do so. The obvious inequity in this situation will continue to keep important non-signatories in opposition to the discriminatory nature of the NPT.",

In other words, my concern is as much with the activities of nuclear weapon states signatory to the NPT as with the possible emergent nuclear weapon states.

The importance of this difference in emphasis is that all too often the non-proliferation measures advanced by nuclear weapon states strongly suggest that states which covet nuclear weapons should be regarded as pariahs. My point is that this excoriation will be treated with the contemptuous rejection it deserves if the current nuclear weapon states continue with the policy best summed up in the epigram: "Our bombs, okay. Your bombs, no way."

DAVID LOWRY

Energy Research Group,

The Open University,

Walton Hall,

Milton Keynes MK7 6AA, UK

\section{Homer's sea}

SIR - Homer's phrase oinopa ponton contains no reference to colour; "wine-dark" is an interpretative English translation (a pretty one, admittedly). It is surely more likely that the phrase meant something like "wine-faced" (ops, face), that is "winesurfaced". The point of similarity was between the moving and frothy surface of the sea and the bubbly surface of wine, when freshly poured into a goblet or cup of metal or pottery and seen by the drinker from above. Homeric men did not drink out of glasses, and anyone who pours out a goblet of wine and quaffs it will see an opaque liquid with "bubbles winking at the brim". It is a sight the drinker may remember when he sees the sea.

JASPER GRIFFIN

Balliol College,

Oxford OXI 3BJ, UK

\section{Black as grapes}

SIR - In the letter from me which you printed (Nature 17 May, p.204) on the meaning of Homer's "wine-dark" sea, you omitted ten words (by a parableptic error) and turned one of my sentences into a non sequitur.

The sentence (in the final paragraph) should have read: 'At Iliad 18.562 we find

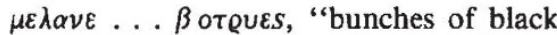
grapes", and Simonides uses $\beta$ ot@us with

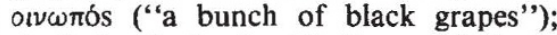
similarly, Sophocles (Oedipus at Colonus 674-675) applies oเv $\omega \psi$ to ivy-berries. You omitted the part of the sentence dealing with Simonides.

The point is that Homer uses the adjective $\mu$ é $\lambda \alpha$ s ("black") to describe grapes; Simonides uses the same word for grapes with the adjective oıv $\omega \pi$ ós ("winecoloured"); and Sophocles uses the similar

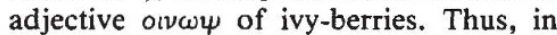

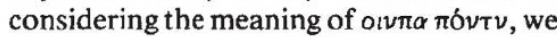
should bear in mind that otv $\psi$ and its kindred words have definite associations with blackness elsewhere.

Martin PUlbrook Department of Ancient Classics, St Patrick's College,

Maynooth,

Co. Kildare, Ireland

This correspondence is not yet closed Editor, Nature. 